\title{
ROLE OF WELDING FLUX IN FORMATION OF WELD METAL DURING ARC WELDING OF HIGH-STRENGTH LOW-ALLOY STEELS
}

\author{
V.V. GOLOVKO, S.N. STEPANYUK and D.Yu. ERMOLENKO \\ E.O. Paton Electric Welding Institute, NASU \\ 11 Bozhenko Str., 03680, Kiev, Ukraine. E-mail: office@paton.kiev.ua
}

\begin{abstract}
Analysis of research results in area of welding metallurgy of high-strength low-alloy (HSLA) steels showed a change of role of welding flux in providing of weld metal quality indices. It is concluded that current welding fluxes should actively participate in processes of weld pool refining, regulation of metallurgical processes of formation of non-metallic inclusions (NMI), having certain composition, morphology and nature of distribution in solid solution, in order to provide necessary structural composition of weld metal and complex of its mechanical properties in welding of HSLA steels. Existing industrial experience allowed the authors determining that agglomerated fluxes have significant advantage in producing the welds with predicted complex of NMI. These fluxes are characterized by high technological flexibility due to regulation of their oxidizing ability, possibility to effect formation of NMI of certain composition and morphology in the welds. Welded joints, produced using these type fluxes, receive the complex of mechanical properties at the level of base metal values. 13 Ref., 7 Figures.
\end{abstract}

Key words: high-strength low-alloy steel, welding, welding flux, non-metallic inclusions, microstructure, mechanical properties

Today steels are still the most widespread structural material in building, machine building and power engineering, regardless the numerous predictions of rapid growth in application of polymeric materials. It may be assumed that this situation will last in the future decades. Welding takes a strong leading position among the methods of joining of steel parts, and arc welding remains the main technology in this field. Analysis of consumption of welding consumables for arc methods of welding during the last decade showed that submerged-arc welding covers $7-10 \%$ of total volume of arc methods, and there are no reasons of significant change of such situation.

Submerged-arc welding, appeared in the 1930s of XX century, went through a stage of intensive development, in course of which deep fundamental investigations of metallurgical, electric and physical-chemical processes were carried out. They formed a basis for wide implementation of automatic welding in different branches of industry to the middle of the 1970s. The investigations carried during these years in combination with accumulation of practical experience of application of fluxes and improvement of technology for production of quality steels promoted a change in determination of flux role in process

(c) V.V. GOLOVKO, S.N. STEPANYUK and D.Yu. ERMOLENKO, 2014 of weld formation. If the flux has a role of passive protection of weld pool from ambient atmosphere and working personnel from arc influence at initial stage of development, then in recent years the flux became an active participant of metallurgical processes taking place in zone of arcing and liquid pool.

Requirements to operation of welded structures determine the necessity of ensuring of service properties of the welded joints at the level of current high-strength steels, therefore the flux in combination with electrode wire should provide alloying, microalloying, modifying and refining of the weld metal. At that, high welding technological properties of the flux should be provided in order to receive quality welds in wide range of modes and welding technologies.

Rolled sheets of low-alloy steels, used at present time for manufacture of welded structures, differ by combination of high indices of strength, ductility and toughness due to formation of fine grain (up to $1 \mu \mathrm{m}$ ) ferrite-bainite or bainitemartensite microstructure. Welded joints of such steels should have the complex of mechanical properties at the level of base metal values. The welding fluxes in this case take the leading role in producing of necessary microstructure of weld metal and mechanical properties of welded joint.

Number of works is dedicated to investigation of conditions of microstructure formation in HSLA steel weld metal. It was determined as a result of their performance that non-metallic inclusions (NMI) [1-4] are one of the factors, hav- 


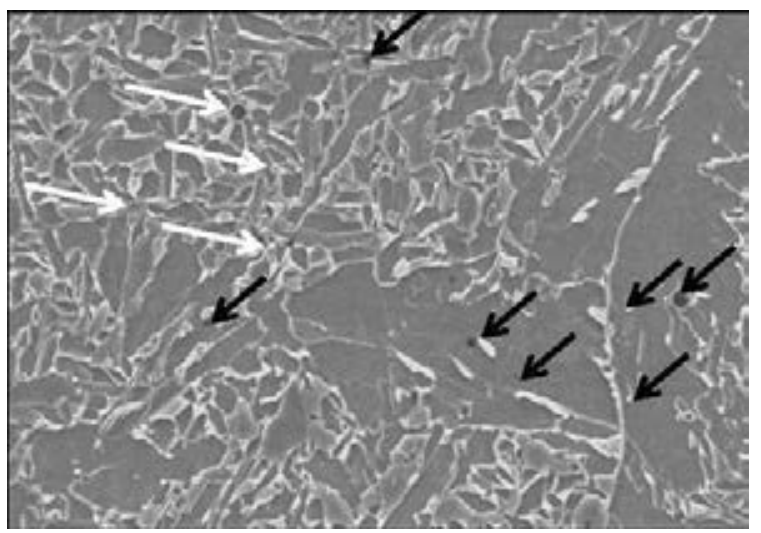

Figure 1. Microstructure $(\times 1000)$ of HSLA steel weld metal (SEM JSM-35): light arrows - ferrite-forming NMI in process of re-solidification; dark - other NMI

ing defining effect on structure. Current fluxes should protect weld pool from ambient atmosphere as well as set required level of oxygen potential of slag phase [5] and together with low-alloy wire promote formation of NMI of predicted amount, composition and size [6]. The weld metal, produced in submerged-arc welding of current HSLA steels, contains $0.02-0.04 \%$ of oxygen and less than $0.01 \%$ of sulfur. Using known expression $V_{\mathrm{NMI}}=5.5[\% \mathrm{O}+\% \mathrm{~S}]$, it can be determined that $0.15-0.30 \mathrm{vol} \%$ of NMI corresponds to given content of oxygen and sulfur. However, only around $30 \%$ of them ( $\mathrm{Fi}^{-}$ gures 1 and 2) actively effect nucleation of ferrite phase [7,8].

The most efficient in this relation are inclusions of $0.3-1.0 \mu \mathrm{m}$ size, having specific morphology [9]. Nuclei of NMI formation in the weld metal are refractory oxides (for example $\mathrm{Al}_{2} \mathrm{O}_{3}$ ), which are present in form of crystals in weld pool liquid metal. When titanium oxide precipitates on the surface of refractory inclusion, then zones with reduced content of alloying elements, having high mobility in $\gamma$-phase, can be formed in adjacent areas of solid solution. The inclusions of given type are the most efficient centers of nucleation of bainite microstructure [9, 10].

Deoxidizing elements such as aluminum, silicon, titanium and manganese are used in metallurgy for refining of iron-based alloys. Technology of manufacture of agglomerated fluxes allows regulating the value of their oxygen potential in wide limits [11]. Regulation of oxygen content in the weld metal, due to change of oxidizing ability of slag phase, in combination with introduction of active deoxidizers in the flux composition provides for the possibility of application of agglomerated fluxes not only for reduction of NMI volume fraction in the weld, but also formation of the inclusions of specific size and composition (Figures 3 and 4).

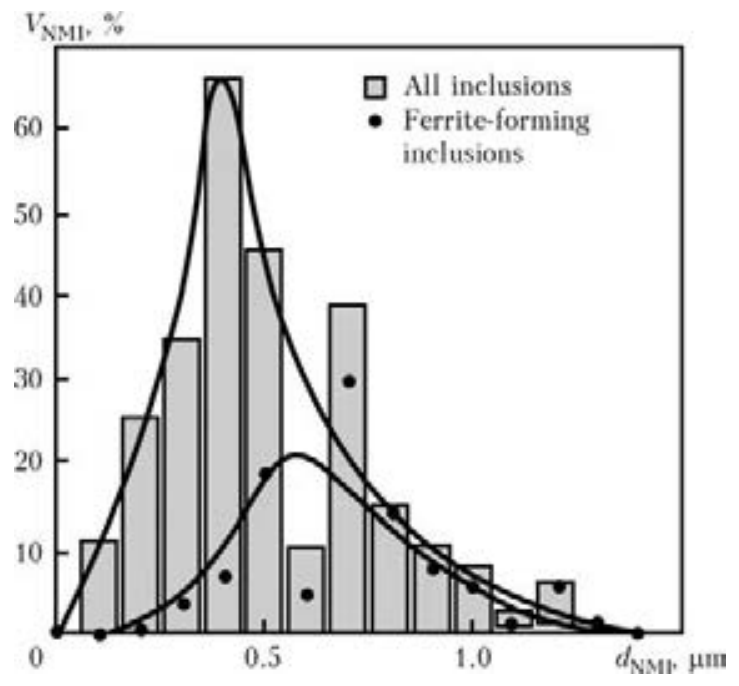

Figure 2. Block diagram of size distribution of all inclusions and inclusions, being the centers of nucleation acicular ferrite in HSLA steel weld metal [9]

Using of such type fluxes in arc welding significantly expands the field of application of methods of predictable effect on formation of NMI of specific composition and morphology in the weld metal [12]. Welded joints in this case receive the complex of mechanical properties at the level of values of HSLA steels [13]. Reduction of oxygen content in titanium-alloyed welds decreases NMI average size as well as rise precipitation of titanium compounds on the surface of refractory inclusions of $\mathrm{Al}_{2} \mathrm{O}_{3}$ type. Analysis of chemical composition of NMI of such morphology and surrounding them metallic matrix, carried out using microprobe for X-ray spectrum analysis, showed that the inclusions containing thin film of titanium compound on their surface have higher concentration of manganese in external layer and reduced content of manganese in zones of solid solution adjacent to the inclusion

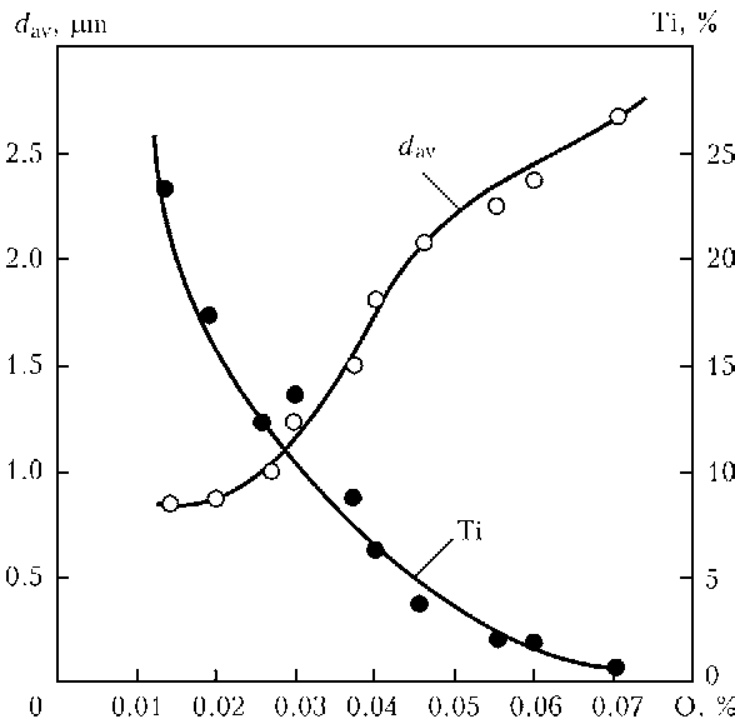

Figure 3. Effect of oxygen content in weld metal on average size of NMI and content of titanium in them 


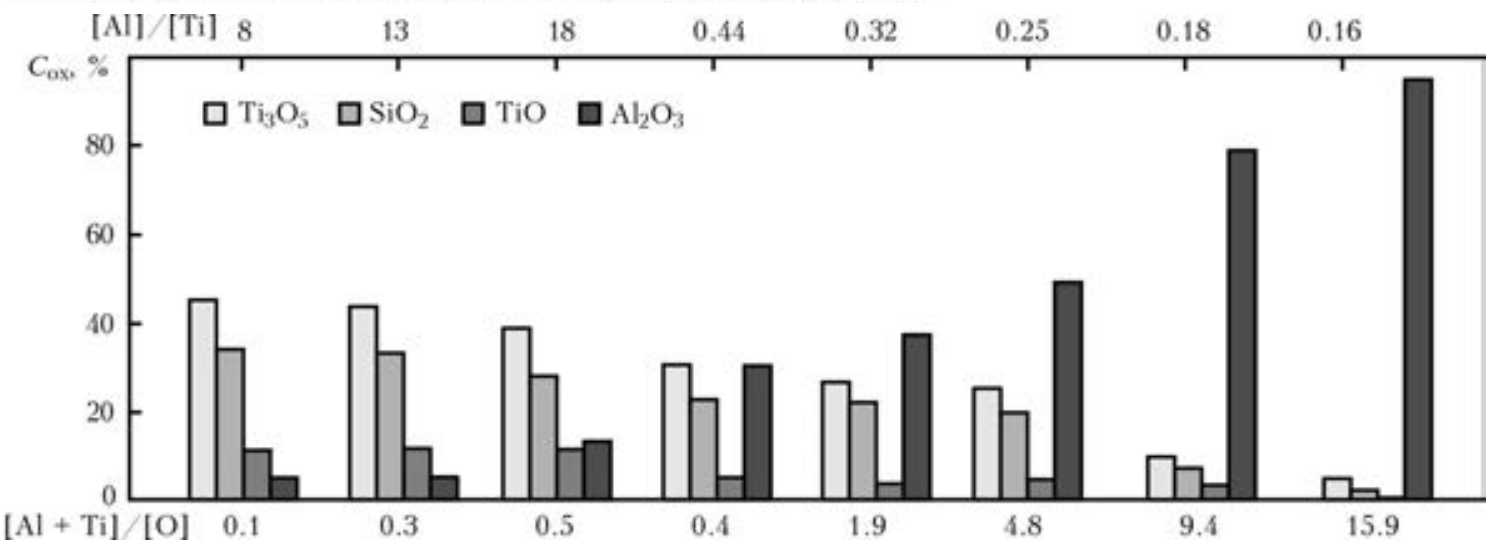

Figure 4. Change of NMI content in weld metal depending on oxidizer/deoxidizer relationship in weld pool

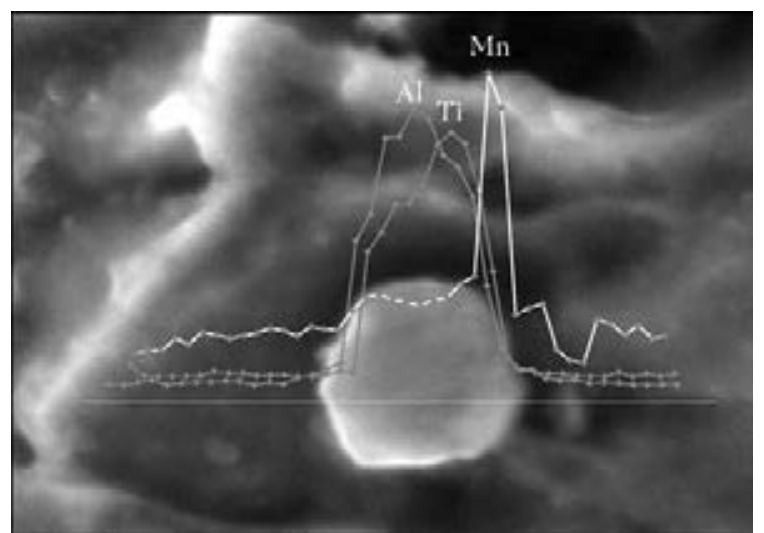

Figure 5. Distribution of elements in NMI and adjacent zones of solid solution

(Figure 5). Inclusion of such morphology promotes for formation of ferrite phase of increased toughness in the process of $\gamma \rightarrow \alpha$ transformation (Figure 6).

Complex of mechanical properties of the weld is determined by combination of its structure constituents. Rise of portion of microstructural fractions of increased hardness results in growth of indices of metal strength (Figure $7, a$ ) and high content of microstructures, forming in $\gamma \rightarrow \alpha$

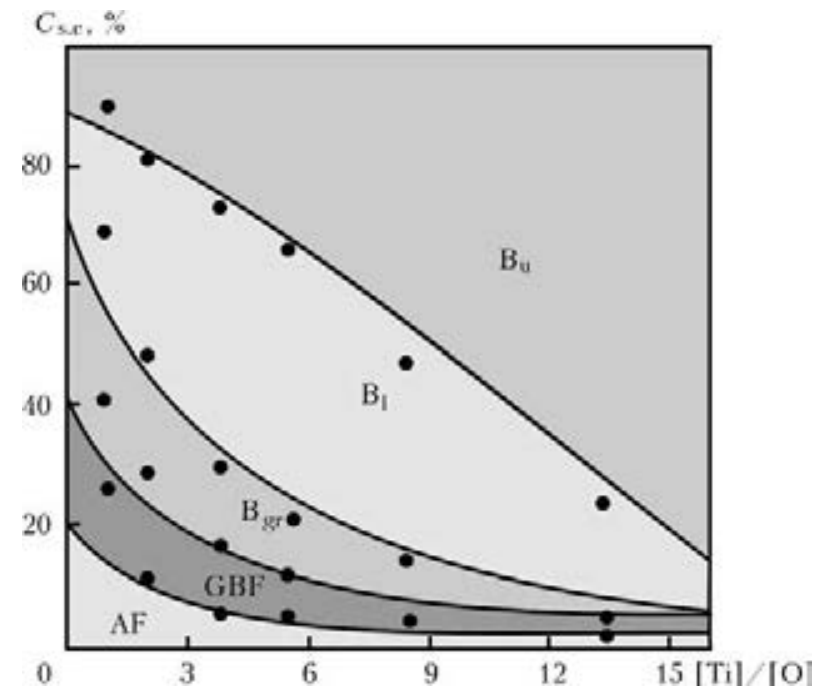

Figure 6. Effect of titanium/oxygen relationship in NMI on content of structural constituents and resistance to weld metal fracture

transformation low temperature zone, characterize by brittle fracture resistance at low climate temperatures (Figure $7, b$ ). Optimum combination of indices of strength, toughness and duc-
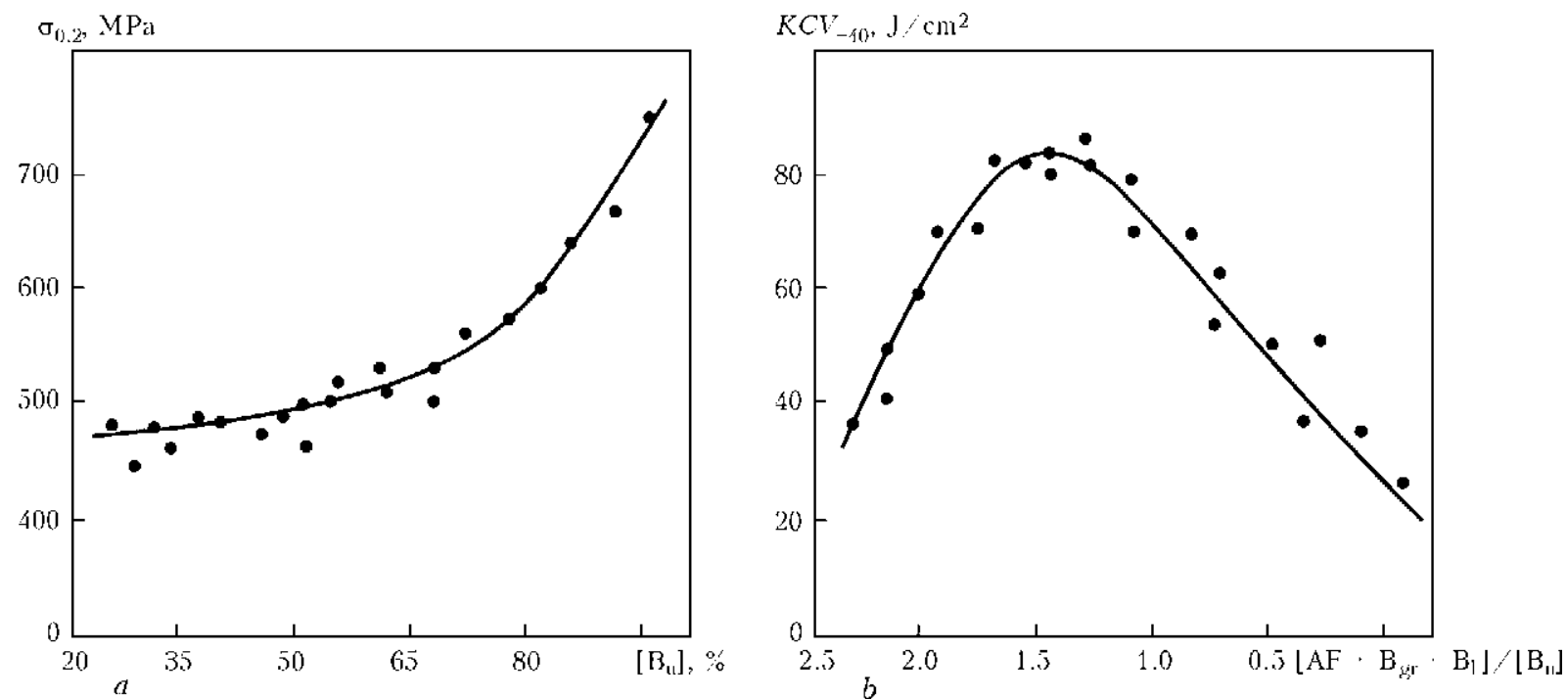

Figure 7. Effect of relationship of structural constituents on yield strength $(a)$ and impact toughness $(b)$ of weld metal 
tility is determined by complex of given structural constituents for each separate case.

As shown by data in Figures 6 and 7, increase of content of such tough constituents as acicular and grain-boundary ferrite, granular and lower bainite up to $60 \%$ provides for growth of impact toughness of weld metal, and at that yield strength does not exceed 500-550 MPa level, typical for welds with ferrite structure. Growth of portion of upper bainite in weld microstructure promotes for rise of indices of strength, but reduces impact toughness at low temperatures.

\section{Conclusion}

Research investigations and significant practical experience in area of welding of HSLA steels resulted in obvious change of role of welding flux in providing of weld metal quality. Current welding fluxes should actively participate in weld pool refining, regulation of metallurgical processes of formation of NMI, having specific composition, morphology and nature of distribution in solid solution, in order to provide necessary structural composition of the weld metal and complex of its mechanical properties in welding of HSLA steels. The industrial experience showed that agglomerated fluxes, characterizing by high technological flexibility due to their oxidizing ability, have significant advantage in this relation. Welded joints, produced using these type fluxes, possess the complex of mechanical properties at the level of values of HSLA steels.

1. Zhang, L., Thomas, B.G. (2003) State-of-the-art in evaluation and control of steel cleanliness: Review. ISIJ Int., 43(3), 271-291.
2. Shin, S.Y., Oh, K., Lee, S. et al. (2011) Correlation study of microstructure, hardness and Charpy impact properties in heat affected zones of three API X80 line pipe steels containing complex oxides. Metal Materials Int., 17(1), 29-40.

3. Zinngrebe, E., Van Hoek, C., Visser, H. et al. (2012) Inclusion population evolution in Ti-alloyed Al-killed steel during secondary steelmaking process. ISIJ Int., 52(1), 52-61.

4. Wegrzyn, T. (2011) Proposal of welding methods in terms of the amount of oxygen. Ibid., 47(1), 57-61.

5. Golovko, V.V. (2006) Influence of oxygen potential of welding fluxes on solid solution alloying in weld metal. The Paton Welding J., 10, 7-10.

6. Golovko, V.V., Pokhodnya, I.K. (2013) Effect of non-metallic inclusions on formation of structure of the weld metal in high-strength low-alloy steels. Ibid., 6, 2-10.

7. Lee, T.K., Kim, H.J., Kang, B.Y. et al. (2000) Effect of inclusion size on the nucleation of acicular ferrite in welds. ISIJ Int., 40, 1260-1268.

8. Grong, O., Kolbeinsen, L., Eijk, C. et al. (2006) Microstructure control of steels through dispersoid metallurgy using novel grain refining alloys. Ibid., 46(6), 824-831.

9. Sarma, D.S., Karasev, A.V., Jonsson, P.G. (2009) On the role of non-metallic inclusions in the nucleation of acicular ferrite in steels. Ibid., 49(7), 1063-1074.

10. Seo, J.S., Kim, H.J., Lee, C. (2013) Effect of Ti addition on weld microstructure and inclusion characteristics of bainitic GMA welds. Ibid., 53(5), 880-886.

11. Golovko, V.V., Podgaetsky, V.V., Bondarenko, T.P. (1993) Oxidability of slag melts of system $\mathrm{MgO}-$ $\mathrm{Al}_{2} \mathrm{O}_{3}-\mathrm{SiO}_{2}-\mathrm{CaF}_{2}$. Avtomatich. Svarka, 9, 28-30.

12. Golovko, V.V., Kostin, V.A., Zhukov, V.V. et al. (2010) Influence of alloying with manganese and titanium on peculiarities of austenite decomposition in low-alloy weld metal. Vestnik Chernig. GTU, 45, 125-133.

13. Golovko, V.V. (2012) Agglomerated fluxes in local welding production (Review). The Paton Welding J., 2, 33-35. 